\title{
A novel type I interferon, interferon alphaomega, shows antiviral activity against foot-and-mouth disease virus in vitro
}

\author{
Shi-fang Li ${ }^{\mathrm{a}, \mathrm{b}, 1}$, Mei-jiao Gong ${ }^{\mathrm{a}, \mathrm{c}, 1}$, Yin-li Xie ${ }^{\mathrm{a}, \mathrm{b}}$, Jun-jun Shao ${ }^{\mathrm{a}, \mathrm{b}}$, Fu-rong Zhao ${ }^{\mathrm{a}, \mathrm{b}}$, \\ Yong-guang Zhang ${ }^{\mathrm{a}, \mathrm{b}}$, Hui-yun Chang ${ }^{\mathrm{a}, \mathrm{b}, *}$ \\ ${ }^{a}$ State Key Laboratory of Veterinary Etiological Biology, OIE/National Foot-and-Mouth Disease Reference Laboratory, Lanzhou Veterinary Research Institute, Chinese \\ Academy of Agricultural Sciences, Lanzhou, 730046, Gansu, China \\ ${ }^{\mathrm{b}}$ Jiangsu Co-innovation Center for Prevention and Control of Important Animal Infectious Diseases and Zoonoses, Yangzhou, Jiangsu, 225009, China \\ ${ }^{\mathrm{c}}$ College of Veterinary Medicine, Gansu Agricultural University, Lanzhou, 730070, China
}

\section{A R T I C L E I N F O}

\section{Keywords:}

Type I interferon

PoIFN- $\alpha \omega$

Foot and mouth disease virus

Interferon stimulated genes

Antiviral activity

IFN- $\mu$

\begin{abstract}
A B S T R A C T
Recently, a novel type I interferon alphaomega (IFN- $\alpha \omega)$, also known as IFN- $\mu$, was identified. However, the biological activity of IFN- $\alpha \omega$ remain poorly understood. In this study, the porcine IFN- $\alpha \omega$ (PoIFN- $\alpha \omega)$ was expressed, purified, and its antiviral activities assessed by its ability to inhibit the cytopathic effect caused by FMDV on IBRS-2 cells. In addition, q-PCR was used to evaluate the expression of IFN-stimulated genes induced by PoIFN- $\alpha \omega$. It was found that PoIFN- $\alpha \omega$ exerted effective antiviral activity against FMDV pre- and post-infection. Additionally, PoIFN- $\alpha \omega$ induced the transcription of IFN-stimulated genes, including Mx1, ISG15, OAS1, and PKR genes. Our study reported a new indication of PoIFN- $\alpha \omega$ as an effective anti-FMDV agent for the first time.
\end{abstract}

\section{Introduction}

Interferons (IFNs) constitute the first line of defense against infection. There are three types of IFNs, type I, II, and III, generally classified according to their different cell surface receptors [1]. Of these, the majority of IFNs are classified as type I IFNs. In humans, type I IFNs have multiple subtypes including, IFN- $\alpha$ and its subclasses as well as a single gene locus encoding IFN- $\beta$, IFN- $\varepsilon$, IFN- $\kappa$, and IFN- $\omega[2,3]$. However, in pigs there are several subtypes, including 17 subclasses for IFN- $\alpha, 7$ subclasses for IFN- $\omega$, and 11 subclasses for IFN- $\delta$, as well as a single subtype of IFN- $\beta$, IFN- $\varepsilon$, and IFN- $\kappa$, as shown in Fig. 1. Recently, a novel type I IFN both in pigs and cows, termed IFN- $\alpha \omega$ was described [4], while, Detournay et al. [5], preferred to calling this type I IFN as IFN- $\mu$. It was found to be located on a separate branch to both IFN- $\alpha$ and IFN- $\omega$, with IFN- $\alpha \omega$ sharing $\sim 65 \%$ nucleic acid similarity and $50 \%$ amino acid identity to both subtypes [3]. Similar to IFN- $\alpha$, IFN- $\alpha \omega$ has been found to have similar induction patterns, with IFN- $\alpha \omega$ mRNA levels increasing in the presence of a viral infection such as sendai virus, equine herpes virus 1 or porcine reproductive and respiratory syndrome virus [3,5]. Additionally, it has been noted that oligodeoxyribonucleotide or poly U/LyoVec induction of equine peripheral blood mononuclear cells occurred in the presence of IFN- $\alpha \omega$, however, this
IFN was not found to be expressed in vivo by the EEL cells [5]. Interestingly, IFN- $\alpha \omega$ mRNA was found to be expressed in the skin from healthy pigs in a higher level compared to the intestine, lymph nodes, and spleen [3]. Furthermore, the recombinant PoIFN- $\alpha \omega$ when expressed in human cells, was found to have a high antiviral activity against porcine reproductive and respiratory syndrome virus in Marc145 cells, however only a low activity against antivesicular stomatitis virus was detected in PK-15 cells [3]. In spite of this, the study of the role of IFN- $\alpha \omega$ in viral defense is limited especially in comparison to IFN- $\alpha$ and IFN- $\beta$, the most well-known and studied of the type I IFN classes. Due to the increasing needs in controlling viral diseases, such as foot-and-mouth disease (FMD), it is important to develop our knowledge of the different types of activity for the novel type I IFNs, and to further explore their potential application as therapeutics for controlling viral infections [3].

FMD is one of the most contagious vesicular diseases of clovenhoofed animals in the world, causing severe social, political, and economic losses to stock breeding [6]. The causative agent, FMDV, is a member of the Aphthovirus genus in the Picornaviridae family and is a highly variable positive-sense single-stranded RNA virus [7]. Owing to its high morbidity and rapid spread between susceptible animals, FMD is listed by the World Organization for Animal Health (OIE). There are

\footnotetext{
* Corresponding author. No.1 Xujiaping, Yanchagnbao, Chengguan District, Lanzhou 730046, Gansu, China.

E-mail address: changhuiyun@caas.cn (H.-y. Chang).

${ }^{1}$ These authors contributed equally to this paper.
} 


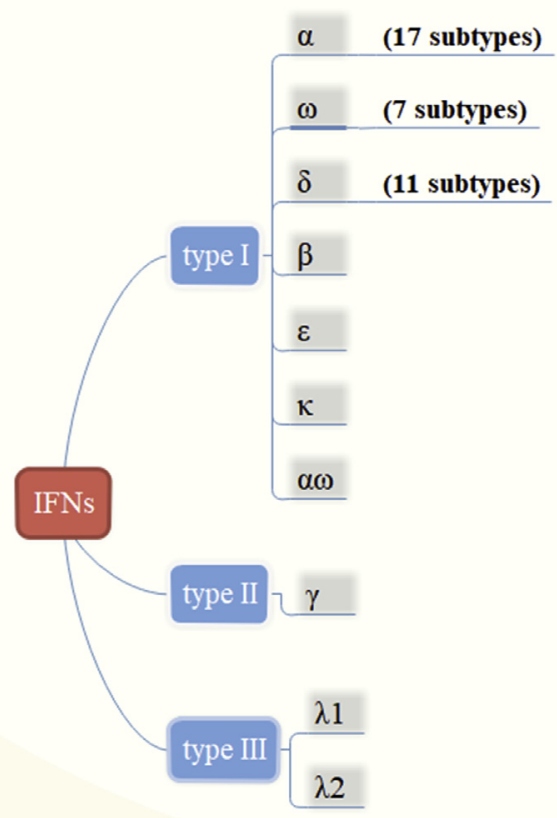

Fig. 1. The classification of porcine interferons.

seven serotypes of FMDV (A, O, C, Asia1, SAT1, SAT2, and SAT3) with multiple subtypes for each of these serotypes also characterized. Currently, vaccines against FMDV have been developed to control FMD dissemination; however, the diverse serotypes and their subtypes are difficult to account for and the vaccine takes at least 7-days to trigger an immune response after being administered [8,9]. Therefore, there is a great need for novel antiviral agents for rapid protection for the animals, and to reduce the spread of FMDV during outbreaks, until vaccine-induced protective immunity can occur [9]. To date, the antiviral activities of only IFN- $\alpha, \beta, \tau, \delta, \omega$, IFN- $\gamma$, and IFN- $\lambda$ against FMDV have been studied [8-12]. However, with the response of IFN- $\alpha \omega$ to FMDV infection remaining poorly understood and the antiviral activity of IFN$\alpha \omega$ yet investigated. In this study, PoIFN- $\alpha \omega$ was expressed in Escherichia coli using the pET-30a vector and purified by Ni-NTA metal affinity chromatography. In addition, the antiviral activity of PoIFN- $\alpha \omega$ against FMDV in the IBRS-2 cells was evaluated.

\section{Materials and methods}

\subsection{Experimental materials}

pET30a ( +) plasmid vector and Escherichia coli BL21 (DE3) cells were the products of Solarbio (Beijing, China). Ni-NTA were purchased from GE for purification purpose. IPTG, Triton X-100 and anti-poly histidine antibody were all purchased from Sigma-Aldrich Co. LLC. Rabbit hyper-immune serum raised against type A FMDV (A/GD/MM/ CHA/2013) were kindly provided by Guang-qing Zhou (OIE/National Foot-and-Mouth Disease Reference Laboratory). Peroxidase-Conjugated Goat anti-Mouse IgG $(\mathrm{H}+\mathrm{L})$ and Rabbit anti-mouse His was obtained from (ZSGB, Beijing, China). The Genscript ToxinSensor ${ }^{\mathrm{TM}}$ Chromogenic LAL Endotoxin Assay Kit for endotoxin level determination were purchased from Genscript (New Jersey, USA). DAB were purchased from Boster (Wuhan, China) for western blot imaging. Bradford Protein Assay kit was purchased from Beyotime (Shanghai, China). PrimeScript $^{\mathrm{TM}}$ RT reagent kit containing gDNA Eraser and SYBR Premix Ex TaqTM ${ }^{I I}$ (Tli RNaseH Plus) were purchased from TaKaRa (Dalian, China). MTS Assay Kit was obtained from Abcam (USA). IBRS-2 cells were maintained in our laboratory. DMEM and Fetal bovine serum were purchased from (Gibco, Grand Island, NY). The serotypes of FMDVs used in this study were O/MYA98/BY/2010 and A/GD/MM/CHA/ 2013, they were preserved and provided by OIE/National Foot-andMouth Disease Reference Laboratory of China, and their TCID $_{50}$ were calculated according to the Reed and Muench method. All the other chemicals used in this report were of analytical grade and commercially available.

\subsection{PoIFN- $\alpha \omega$ expression}

Mature IFN- $\alpha \omega$ cDNA (Gene accession GQ415072.1) was codonoptimized for $E$. coli expression (the optimized sequence is available in S1) and synthesized by Shanghai Sangon Biotechnology Co., Ltd. (Shanghai, China). The IFN- $\alpha \omega$ DNA fragment was enzymatically cut from the host vector with EcoR I and Hind III and inserted into a pET30a (+) plasmid vector for further overexpression trials. After the DNA sequence was confirmed by DNA sequencing by Shanghai Sangon Biotechnology Co., Ltd. (Shanghai, China), the plasmid was transformed into E. coli BL21 (DE3) competent cells. A single clone of the transformed cells was inoculated into Luria-Bertani (LB) $(5 \mathrm{~mL})$ and cultured at $37^{\circ} \mathrm{C}$ with shaking $(220 \mathrm{rpm})$. Once the optical density $\left(\mathrm{OD}_{600 \mathrm{~nm}}\right)$ reached $0.4-0.6$, the cells were induced with $1 \mathrm{mM}$ IPTG and were grown for an additional $8 \mathrm{~h}$ at $37^{\circ} \mathrm{C}$ with shaking $(220 \mathrm{rpm})$. The induced cells were then collected and lysed by sonication (at $200 \mathrm{~W}, 2 \mathrm{~s}$ on and $2 \mathrm{~s}$ off). Following centrifugation $(11,000 \times \mathrm{g}, 10 \mathrm{~min})$, the cell pellets and supernatants were examined with $12 \%$ SDS-PAGE. Western blotting was performed using anti-poly histidine antibody and rabbit anti-mouse His to detect the expression of the recombinant PoIFN- $\alpha \omega$ protein using DAB, as described previously [10].

\subsection{Purification of PoIFN- $\alpha \omega$}

After centrifugation $(11,000 \times g, 10 \mathrm{~min})$, the cell pellet containing recombinant PoIFN- $\alpha \omega$ was resuspended in IB washing buffer $(20 \mathrm{mM}$ Tris, $500 \mathrm{mM} \mathrm{NaCl}, 1 \%$ Triton X-100, $10 \mathrm{mM}$ EDTA, $4 \mathrm{M}$ urea) and centrifuged again; this was repeated five times. Following the washes, the pellet containing the inclusion bodies was solubilized in IB solubilization buffer ( $8 \mathrm{M}$ urea, $2 \mathrm{mM} \beta$-mercaptoethanol, $20 \mathrm{mM}$ Tris- $\mathrm{HCl}$, $100 \mathrm{mM} \mathrm{NaH}_{2} \mathrm{PO}_{4} \cdot 2 \mathrm{H}_{2} \mathrm{O}, \mathrm{pH} 8.0$ ) overnight at $4{ }^{\circ} \mathrm{C}$. After centrifugation, $\left(12,000 \times g\right.$ at $4{ }^{\circ} \mathrm{C}$ for $\left.30 \mathrm{~min}\right)$, the rPoIFN- $\alpha \omega$, now in the supernatant, was purified using Ni-NTA metal affinity chromatography according to the manufacturer's instructions. Briefly, the supernatant was loaded onto the Ni-NTA column, washed with an imidazole gradient from 20 to $200 \mathrm{mM}$ in IB solubilization buffer, and then eluted with $500 \mathrm{mM}$ imidazole in IB solubilization buffer. The purity of the purified protein was measured using $12 \%$ SDS-PAGE. Following this, rPoIFN- $\alpha \omega$ was renatured using dialysis in the buffer, $100 \mathrm{mM}$ Tris, $2 \mathrm{mM}$ EDTA, $1 \%$ glycine, $5 \%$ glycerinum, $\mathrm{pH} 8.1$, under a urea gradient, decreasing the concentration from 4 to $0 \mathrm{M}$. Finally, the concentration of the renatured rPOIFN- $\alpha \omega$ and its endotoxin level were determined using the Bradford Protein Assay kit and Genscript ToxinSensor ${ }^{\mathrm{TM}}$ Chromogenic LAL Endotoxin Assay Kit, respectively, according to each of the manufacturer's instructions.

\subsection{Antiviral activity of PoIFN- $\alpha \omega$ against FMDV}

\subsubsection{Pre-infection antiviral activity of PoIFN- $\alpha \omega$ against FMDV}

The antiviral effects of PoIFN- $\alpha \omega$ against FMDV were measured in IBRS-2 cells. Initially, IBRS-2 cells were seeded in 96-well plates at a density of $3.5 \times 10^{4}$ cells/well. After $24 \mathrm{~h}$, once the IBRS- 2 cells were $90 \%$ confluent, they were inculated with the rPoIFN- $\alpha \omega$ in a 10 -fold serial dilution and left for an additional $24 \mathrm{~h}$ absorption period. After which, the rPoIFN- $\alpha \omega$ was removed, and the cells were washed three times with DMEM. IBRS-2 cells were then immediately infected with $100 \mathrm{TCID}_{50}$ of A/GD/MM/CHA/2010. After a $1 \mathrm{~h}$ absorption period, the infected culture media was removed, and $100 \mu \mathrm{L}$ of clean culture media 
supplemented with $2 \%$ FBS was added. The cells were then allowed to continue incubating at $37^{\circ} \mathrm{C}$ for a further $48 \mathrm{~h}$. Viability of the infected cells was determined with an MTS assay kit, as described by the manufacturer. RNA extraction and quantitative real time PCR were performed as previously described [10], to assay the effects on FMDV RNA replication and the potential broad-spectrum antiviral effects of IFN$\alpha \omega$. In addition, the cells were treated with $200 \mathrm{ng} / \mathrm{mL}$ of rIFN- $\alpha \omega$, the lowest concentration showing $100 \%$ protection from the CPE, and then challenged with the FMDV viral strain O/MY98/BY/2010. Cell viability and relative viral mRNA levels were evaluated as described above.

\subsubsection{Post-infection antiviral activity of PoIFN- $\alpha \omega$ against FMDV}

IBRS- 2 cells were seeded in 96-well plates at a density of $3.5 \times 10^{4}$ cells per well. After $24 \mathrm{~h}$, once the cells reached $90 \%$ confluency they were washed twice with DMEM, and immediately infected with $100 \mu \mathrm{L}\left(100 \mathrm{TCID}_{50} / 100 \mu \mathrm{L}\right)$ of FMDV. After $1 \mathrm{~h}$ absorption at $37^{\circ} \mathrm{C}$, the infected culture media was removed and the cells were washed twice with DMEM. Following this, $100 \mu \mathrm{L}$ of culture media with $2 \%$ FBS was added. Treatment with $200 \mathrm{ng} / \mathrm{mL}$ of rIFN- $\alpha \omega$ was carried out at various time intervals of $0,2,4,8,16$, and $24 \mathrm{~h}$ post infection (p.i) with $\mathrm{A} / \mathrm{GD} / \mathrm{MM} / \mathrm{CHA} / 2010$. The cells were then incubated for a further $72 \mathrm{~h}$ at $37^{\circ} \mathrm{C}$ until the maximum CPE of FMDV was reached. Cell viability and relative viral mRNA levels were determined as described above.

\subsection{IFA}

The monolayers of IBRS-2 cells seeded in 12-well plates inculated with the rPoIFN- $\alpha \omega$ in a 10 -fold serial dilution for $24 \mathrm{~h}$. The cells were washed three times with PBS, and infected with $100 \mathrm{TCID}_{50}$ of A/GD/ $\mathrm{MM} / \mathrm{CHA} / 2010$. Twelve hours post infection, the cells were fixed with 4\%-paraformaldehyde for $15 \mathrm{~min}$ at room temperature. After removing paraformaldehyde, the cells was permeabilized with $0.1 \%$ Triton X-100 for $5 \mathrm{~min}$ at room temperature. After being washed, the cells were blocked with blocking solution (89.7\% PBS, 10\% FBS, 0.3\% Triton X100 ) for $10 \mathrm{~min}$ at room temperature. The cells were then incubated with a 1:150 dilution of rabbit hyper-immune serum raised against A/ $\mathrm{GD} / \mathrm{MM} / \mathrm{CHA} / 2013$ for $1 \mathrm{~h}$ in blocking solution at room temperature. Subsequently, the cells were washed three times with PBS and incubated peroxidase-conjugated goat anti-mouse IgG $(H+L)(1: 200)$ in blocking solution for $1 \mathrm{~h}$ at room temperature. Finally, the cells were counterstained with DAPI and cells were observed with a fluorescence microscope after three washes with PBS.

\subsection{Detection of induced expression of IFN- $\alpha \omega$ in IBRS-2 cells following FMDV infection}

IBRS-2 cell monolayers in 12-well plate at a density of $3.5 \times 10^{5}$, were challenged with $100 \mathrm{TCID}_{50}$ of both FMDV viral strains $\mathrm{O} /$ MYA98/BY/2010 and A/GD/MM/CHA/2013. After $1 \mathrm{~h}$, the viruses were removed and $100 \mu \mathrm{L}$ of culture medium with $2 \%$ FBS was added. After $24 \mathrm{~h}$ the cells were collected, and IFN- $\alpha \omega$ expression levels was determined with q-PCR, with specific primers ( $\alpha \omega \mathrm{F}$ : 5'-AGATCTTCCG CCTCTTCAGCACAA- $3^{\prime}$ and $\alpha \omega R$ : 5'-TTCTGGTTTCCACCCTGACAA CCT-3'), GAPDH (GAPDH-F-5'-TGGYATCGTGGAAGGRCTCAT-3' and GAPDH-R-5'-RTGGGWGTYGCTGTTGAAGTC-3') was used as the reference gene, as described by Sang and others [3].

\subsection{Q-PCR analysis of ISGs expression}

To analyze the expression levels of ISGs, qPCR was used to evaluate the mRNA expression levels of Mx1, 2‘'5`OAS, PKR, and ISG15. IBRS2 cells in 12-well plates were directly treated with medium containing $200 \mathrm{ng} / \mathrm{mL}$ of rPoIFN- $\alpha \omega$ for $24 \mathrm{~h}$, and RNA extraction and reverse transcription were carried out. Q-PCR was conducted using the SYBR Premix Ex TaqTM ${ }^{\text {II }}$ (Tli RNaseH Plus) kit on the Agilent Technologies
Stratagene Mx3005P instrument (Agilent, USA) with gene-specific primer sets described previously [10]. The relative levels of mRNA for the four ISGs were normalized to $\beta$-actin mRNA, which was used as the internal control in each of the samples.

\subsection{Statistical analysis}

Graphical illustrations in this study were performed by GraphPad Prism software. The significance of the differences was conducted by the $t$-test and one-way ANOVA using the SPSS software, followed by Tukey's Post hoc multiple comparison test. All data are presented as means \pm standard deviation ( $\mathrm{n} \geqq 3$ ). Statistically significance is considered by $P<0.05$.

\section{Results and discussion}

As one of the most devastating diseases affecting livestock more effective measures against FMD are needed. Vaccines play an important role in the prevention of a FMDV outbreak, however, protection from FMDV remains incomplete [13]. To date, there are several alternative methods to control this disease effectively, such as mutagenic nucleoside analogs [14], magnesium oxide nanoparticles [15], and small interference RNA [16]. Though, there remains a great need for additional antiviral agents to be developed to reduce the spread of FMDV in outbreak situations.

IFNs as soluble glycoproteins, play a central role in the antiviral defense of a host, by evoking antiviral protein expression. It has been explored as a powerful tool in the prevention of viral infections, such as hepatitis $\mathrm{B}$ and hepatitis $\mathrm{C}$ virus infection. Interestingly, It was demonstrated that FMDV is quite sensitive to IFN [9], and as a result, IFNs, including IFN- $\alpha, \beta, \tau, \delta, \omega$, IFN- $\gamma$, and IFN- $\lambda$ have been shown to be an efficient biotherapeutic option against FMDV both in vitro and/or in vivo [8-12]. However, other IFNs have not yet been widely utilized for viral infections, with one possible reason for this restricted clinical use being that the biological properties of type I IFNs have not yet been investigated thoroughly [17]. Therefore, to further develop new and more effective immunotherapies against viruses, a more detailed in vivo and in vitro analysis of the antiviral effects of type I IFNs, especially novel IFN, is required.

Recently, IFN- $\alpha \omega$ was identified, however, there is very limited information regarding its biological activity. Therefore, to determine the biological characteristics of PoIFN- $\alpha \omega$ and its potential protective effect against FMDV, we expressed rPoIFN- $\alpha \omega$ in a prokaryotic expression system. First of all, the mature PoIFN- $\alpha \omega$ DNA was inserted into the pET30a (+) plasmid vector, confirmed with DNA sequencing, and transformed into E. coli BL21 (DE3) competent cells. Subsequently, the expression of PoIFN- $\alpha \omega$ protein was examined. As seen in Fig. 2A, after the cells were lysed by sonication, rPoIFN- $\alpha \omega$ was observed to be mainly expressed in an insoluble form, which was confirmed with western blot (Fig. 2B). Purification of the rHis-PoIFN- $\alpha \omega$ protein achieved a $95 \%$ purity. The endotoxin level of purified rPoIFN- $\alpha \omega$ was $0.5 \mathrm{EU} / \mathrm{mL}$, indicating that the purified rPoIFN- $\alpha \omega$ protein was suitable for subsequent use. And then, the biological activities of PoIFN- $\alpha \omega$ was determined using an MTS assay and q-PCR in vitro. To investigate the minimum antiviral protection concentration of rPoIFN- $\alpha \omega$ for IBRS2 cells against FMDV, a serial dilution range was used from 0.002 to $200 \mathrm{ng} / \mathrm{mL}$. With pre-infection treatment with $200 \mathrm{ng} / \mathrm{mL}$ of PoIFN- $\alpha \omega$, significant protection for cells from CPE $(P<0.01)$ (Fig. 3A), other concentrations of $\mathrm{rPoIFN}-\alpha \omega$ were found to not provide any protection to the cells from CPE caused by FMDV A/GD/MM/CHA/2013. Interestingly, it seems that a higher efficacy was observed compared to IFN$\delta 8$ in terms of the lowest concentration which provide $100 \%$ protection against FMDV-induced CPE in IBRS-2 cells according to our recent studies [10], but lower efficacy than that in IFN- $\tau 4$ [8]. Previously, we found that IFN- $\delta$ had broad spectrum antiviral activity on a number of serotypes of FMDV strains [10] and as expected, IFN- $\alpha \omega$ mainly exerted 


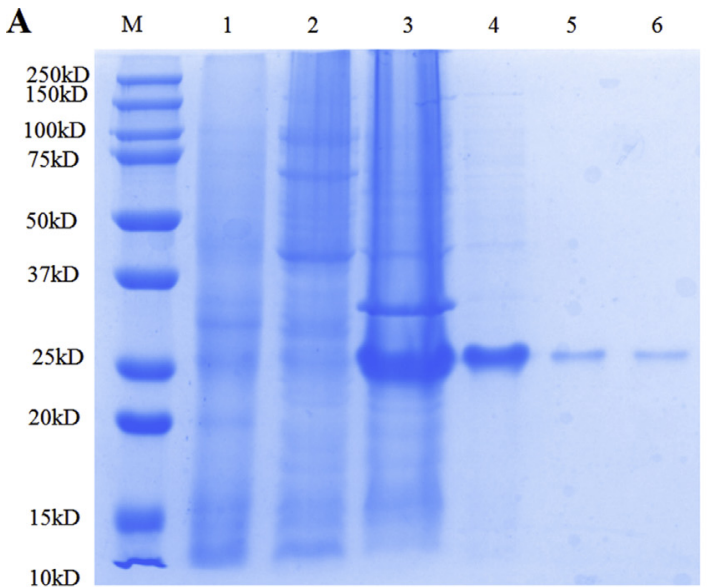

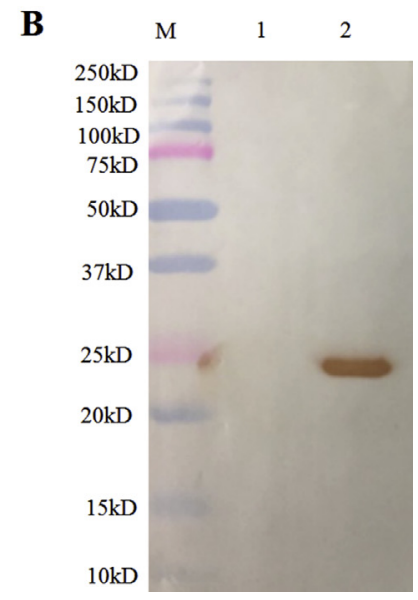

Fig. 2. Expression of rHis-PoIFN- $\alpha \omega$. a. 12\% SDSPAGE analysis of PoIFN- $\alpha \omega$ expression. Lane M: Protein marker, lane 1: Uninduced control, lane 2: Supernatant of sonicated bacterial lysate, lane 3: Pellet of sonicated bacterial lysate, lane 4: Solubilized PoIFN- $\alpha \omega$ inclusion bodies, lane 5: Purified PoIFN$\alpha \omega$ after elution from Ni-NTA column, lane 6: Purified PoIFN- $\alpha \omega$ after refolding. b. Western blot confirmation of rHis-PoIFN- $\alpha \omega$ expression. Lane M: Protein marker, lane1: pET-30a vector after induction, lane 2: Purified PoIFN- $\alpha \omega$ protein. its antiviral activity against type O/MY98/BY/2010 (Fig. 3C and D). To analyze the inhibitory effect of rPoIFN- $\alpha \omega$ on FMDV replication, relative real-time PCR was conducted to determine FMDV viral mRNA levels in IBRS-2 cells, in both rPoIFNaw-treated and non-treated groups. It was found that the viral mRNA levels significantly decreased when the cells were pre-treated with rPoIFN- $\alpha \omega(p<0.01)$ (Fig. 3B and D). As such, the levels of FMDV mRNA in IBRS-2 pre-treated with $200 \mathrm{ng} / \mathrm{mL}$ of PoIFN- $\alpha \omega$ was found to be 5.32-log lower than that found in the non-treated controls. IFA results showed that a weak fluorescent signals was observed in IBRS-2 cells treated with $200 \mathrm{ng} / \mathrm{mL}$ of PoIFN$\alpha \omega$ in comparison to the other treated groups and the non-treated group, which showed a strong fluorescent signals (Fig. 4), these results indicated that PoIFN- $\alpha \omega$ exhibited significant antiviral activity against FMDV in a dose-dependent manner. Additionally, the antiviral activity of rPoIFN- $\alpha \omega$ when used as treatment post infection with FMDV, also showed efficacy in decreasing CPE in infected cells. However, the treatment time post-infection played a key role in decreasing CPE, with treatment groups in which rPoIFN- $\alpha \omega$ was added immediately after infection and up to $8 \mathrm{~h}$ p.i had remarkably decreased cell resulting cytopathies. When IBRS-2 cells were infected with FMDV A/GD/MM/ $\mathrm{CHA} / 2013$ at various time intervals $(0,2,4,8,12,16$ and $24 \mathrm{~h}$ p.i) and then treated with $200 \mathrm{ng} / \mathrm{mL}$ of rPoIFN- $\alpha \omega$, it was found that rPoIFN- $\alpha \omega$ could also provide protection $(P<0.05)$. As shown in Fig. $5 \mathrm{~A}$, rPoIFN- $\alpha \omega$ could significantly protect against FMDV-induced CPE up to $8 \mathrm{~h}$ post-FMDV infection $(P<0.01)$, with a decrease of the viral mRNA from $2.55-\log$ to $2.96-\log$ at 0,2 , and $4 \mathrm{~h}$ p.i, compared to the nontreated controls $(p<0.01)$ (Fig. 5B). While in contrast, there was no significant difference to the CPE and mRNA levels for cells in which rPoIFN- $\alpha \omega$ was added after $8 \mathrm{~h}$ p.i. These results was consistent with the results of Usharani et al. [8] and our previous study [10], showing that IFN- $\alpha \omega$ could also be explored for treating viral diseases during the early stages of infection.

IFN expression is known to be induced when exposed to a pathogen resulting in an infection [1]. However, in fact, different subtypes have been shown to have varying degrees of induction in response to viral infections. For example, in previous reports, IFN- $\varepsilon$ was capable of displaying a positive induction in response to herpes simplex virus 2, Chlamydia muridarum [18] but not in response to simian immunodeficiency virus [19] and Theiler's murine encephalomyelitis virus [20]. Furthermore, IFN- $\omega$ expression didn't alter during lyssavirus infection, while IFN-к mRNA levels were significantly down-regulated [21]. The expression pattern of PoIFN- $\alpha \omega$ in IBRS-2 cells after FMDV infection was detected using real time PCR, with untreated IBRS-2 cells serving as the negative control. PoIFN- $\alpha \omega$ was up-regulated in response
A

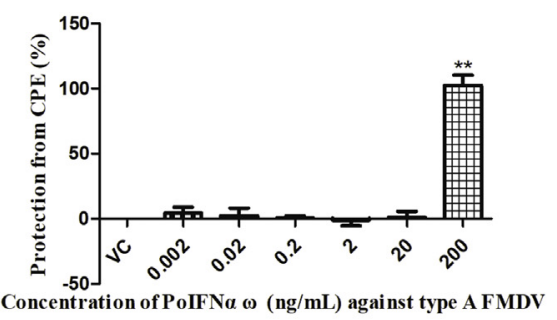

C

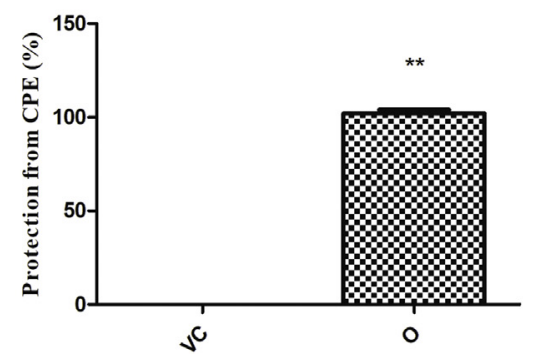

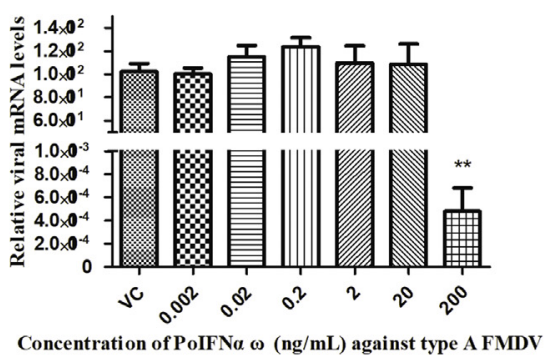

$\mathrm{D}$

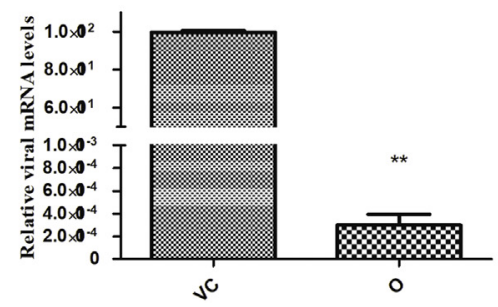

Fig. 3. Antiviral activity of PoIFN- $\alpha \omega$ against FMDV pre-infection. A. CPE reduction by PoIFN- $\alpha \omega$ in IBRS-2 cells in a concentration dependent antiviral activity assay. B. Reduction in FMDV mRNA expression by PoIFN- $\alpha \omega$ in IBRS- 2 cells in a concentration dependent antiviral activity assay. IBRS-2 cells were pre-treated with 10-fold dilutions of PoIFN- $\alpha \omega$ for $24 \mathrm{~h}$ before infection with FMDV A/GD/MM/CHA/ 2013. C. CPE protection assay to evaluate antiviral efficacy of PoIFN- $\alpha \omega$ against FMDV O/MY98/BY/ 2010. D. FMDV mRNA reduction assay to evaluate antiviral efficacy of PoIFN- $\alpha \omega$ against FMDV O/ MY98/BY/2010 infection. IBRS-2 cells were pretreated with $200 \mathrm{ng} / \mathrm{mL}$ of PoIFN- $\alpha \omega$ for $24 \mathrm{~h}$ before infection with FMDV O/MY98/BY/2010. Untreated virus and cell controls were also maintained. Viral control (VC) are IBRS-2 cells infected with FMDV, but without PoIFN- $\alpha \omega$. Values represent the mean \pm SD of three independent tests. ${ }^{*} p<0.05$ compared with the non-treated IBRS- 2 cells. 
Non-tr

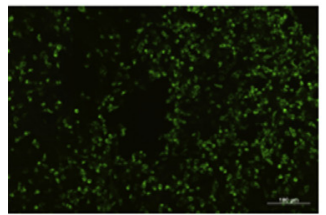

$2 \mathrm{ng} / \mathrm{mL}$

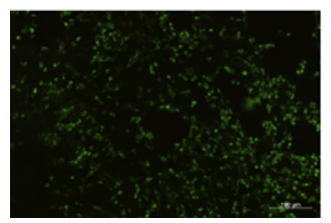

$0.002 \mathrm{ng} / \mathrm{mL}$

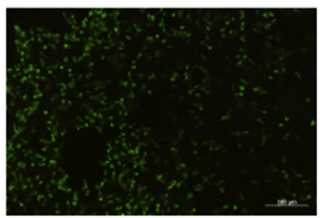

$20 \mathrm{ng} / \mathrm{mL}$

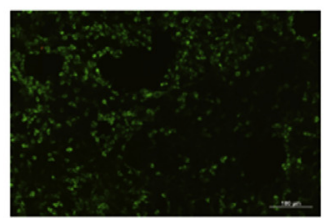

$0.02 \mathrm{ng} / \mathrm{mL}$

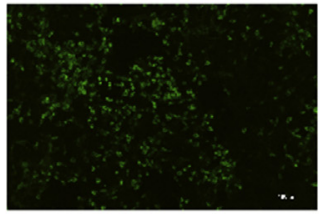

$200 \mathrm{ng} / \mathrm{mL}$

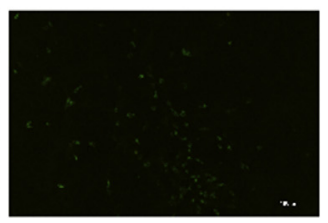

$0.2 \mathrm{ng} / \mathrm{mL}$

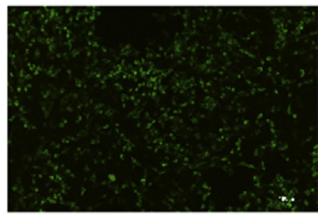

B

A
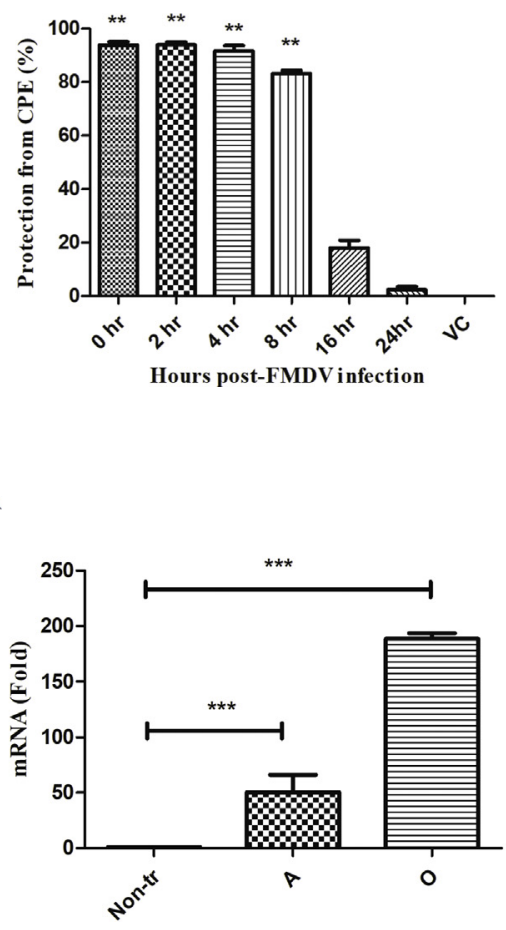

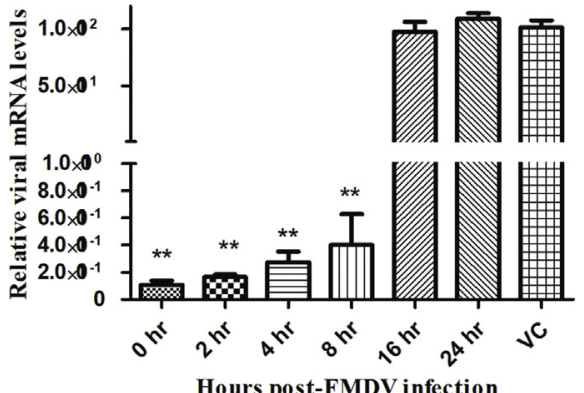

B

Non-treated IBRS-2 cells

IFN- $\alpha \omega$ treated IBRS-2 cells

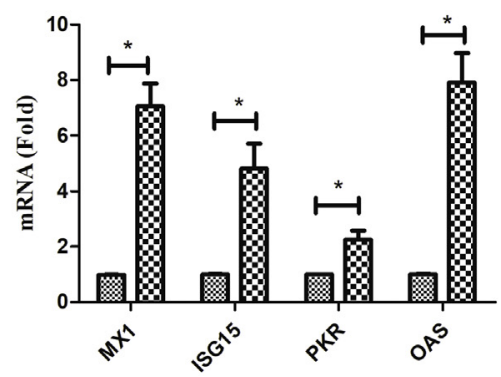

Fig. 4. The FMDV proteins in IBRS-2 cells treated with different concentrations of PoIFN- $\alpha \omega$ were determined by IFA. IBRS2 cells were preincubated with different concentrations of PoIFN- $\alpha \omega$ for $24 \mathrm{~h}$ prior to infection and were infected with $100 \mathrm{TCID}_{50}$ A/GD/MM/CHA/2013 for $12 \mathrm{~h}$. The cells were then counterstained with DAPI and examined using a fluorescent microscope. Scale bars indicate $100 \mu \mathrm{m}$. Non-tr indicates the IBRS-2 cells infected with A/GD/MM/ $\mathrm{CHA} / 2013$ without PoIFN- $\alpha \omega$ treatment.
Fig. 5. Post-infection antiviral activity of PoIFN- $\alpha \omega$ against FMDV A/GD/MM/CHA/2013. A. Protection from CPE in IBRS-2 cells, expressed as the percent protection, compared to the untreated virus. B. Reduction of mRNA levels following treatment with PoIFN- $\alpha \omega$, after infection with FMDV A/GD/MM/CHA/2013. IBRS-2 cells were infected with FMDV A/GD/MM/CHA/2013 and then treated with PoIFN- $\alpha \omega$ at $0,2,4,8,16$ and 24 h p.i. Untreated virus and cell controls were also maintained. VC indicates IBRS-2 cells infected with A/GD/MM/CHA/ 2013, but without PoIFN- $\alpha \omega$ treatment. Values represent the mean $\pm \mathrm{SD}$ of three independent tests. * $p<0.05$ compared with the non-treated IBRS- 2 cells. to both type A and type O FMDV infection ( $p<0.01$ ) (Fig. 6A). PoIFN$\alpha \omega$ gene expression increased by a 50.59-fold with a type A infection, and 188.58-fold with a type O FMDV infection. In this study, IFN- $\alpha \omega$ expression was found to be up-regulated in response to FMDV infection, consistent with previous research, in which IFN- $\alpha$, IFN- $\beta$, IFN- $\gamma$, and IFN- $\lambda$ were also up-regulated during FMDV infection [22]. Furthermore, the IFN- $\alpha \omega$ mRNA level was observed to be higher during a type O FMDV infection compared to a type A FMDV infection (Fig. 6A), therefore it may be thought that a type O FMDV infection is more sensitive to IFN- $\alpha \omega$. It has been demonstrated that IFN exert its antiviral affects by stimulating the expression of ISGs, which inhibit the replication of the invading virus [23]. In this study, to evaluate if rPoIFN- $\alpha \omega$ was able to up-regulate production of antiviral proteins, four ISGs were investigated, Mx1, ISG15, PKR, and OAS1. The mRNA levels of the four genes in IBRS-2 cells were found to be increased at $24 \mathrm{~h}$ after treatment with rPoIFN- $\alpha \omega(p<0.05)$. Specifically, the mRNA level of Mx1, ISG15, PKR, and OAS1 were up-regulated by approximately 7.05, 4.82, 2.25, and 8.91-fold, respectively (Fig. 6B). This indicates that IFN- $\alpha \omega$ may exhibit its antiviral activity by the activation of the type I signalling pathway, a further detailed studies on mechanism of signalling pathway utilized by IFN- $\alpha \omega$ is needed.

In summary, PoIFN- $\alpha \omega$ was successfully expressed, purified. In addition, IFN- $\alpha \omega$ expression in IBRS-2 cells was found to be significantly increased after infection with FMDV as well as rPoIFN- $\alpha \omega$ exhibiting antiviral activity against FMDV. The results of this study provide the foundation for future studies into PoIFN- $\alpha \omega$ as a potential candidate for a novel, and effective antiviral molecule against FMDV and potentially other viral diseases.

\section{Competing interests}

The authors declare that they have no competing interests. 


\section{Acknowledgements}

This work was supported by the National Key Research and Development Program (2017YFD0500902), the Key R\&D Program of Gansu Province of China (Grant No. 17YF1NA070) and the National Pig Industrial System of China (CARS-36-06B).

\section{Abbreviations}

IFNs interferons

FMD foot and mouth disease

SAT southern African Territories

IBRS-2 porcine kidney cell line

Ni-NTA nickel-nitrilotriacetic acid

IPTG isopropyl $\beta$-1-thiogalactopyranoside

DAB 3,3-diaminobenzidine tetrahydrochloride

IB inclusion body

CPE cytopathic effect

ISGs IFN-stimulated genes

PKR Protein Kinase R

qPCR Real time PCR

OAS 2'-5'oligoadenylate synthetase

PBS Phosphate buffered saline.

\section{Appendix A. Supplementary data}

Supplementary data to this article can be found online at https:// doi.org/10.1016/j.micpath.2018.11.040.

\section{References}

[1] S. Pestka, C.D. Krause, M.R. Walter, Interferons, interferon-like cytokines, and their receptors, Immunol. Rev. 202 (2004) 8-32.

[2] A. Takaoka, H. Yanai, Interferon signalling network in innate defence, Cell Microbiol. 8 (2006) 907-922.

[3] Y. Sang, R.R. Rowland, R.A. Hesse, F. Blecha, Differential expression and activity of the porcine type I interferon family, Physiol. Genom. 42 (2010) 248-258.

[4] C.D. Krause, S. Pestka, Evolution of the Class 2 cytokines and receptors, and discovery of new friends and relatives, Pharmacol. Ther. 106 (2005) 299-346.
[5] O. Detournay, D.A. Morrison, B. Wagner, et al., Genomic analysis and mRNA expression of equine type I interferon genes, J. Interferon Cytokine Res. 33 (2013) 746-759.

[6] M.J. Grubman, B. Baxt, Foot-and-mouth disease, Clin. Microbiol. Rev. 17 (2004) 465-493.

[7] E. Domingo, C. Escarmis, E. Baranowski, et al., Evolution of foot-and-mouth disease virus, Virus Res. 91 (2003) 47-63.

[8] J. Usharani, S.Y. Park, E.J. Cho, et al., Antiviral activity of ovine interferon tau 4 against foot-and-mouth disease virus, Antivir. Res. 143 (2017) 134-141.

[9] F. Diaz-San Segundo, M. Weiss, E. Perez-Martin, et al., Antiviral activity of bovine type III interferon against foot-and-mouth disease virus, Virology 413 (2011) 283-292.

[10] S.F. Li, J.J. Shao, F.R. Zhao, et al., Antiviral activity of porcine interferon delta 8 against foot-and-mouth disease virus in vitro, Int. Immunopharm. 59 (2018) 47-52.

[11] M.P. Moraes, S.T. de Los, M. Koster, et al., Enhanced antiviral activity against footand-mouth disease virus by a combination of type I and II porcine interferons, J. Virol. 81 (2007) 7124-7135.

[12] S.F. Li, F.R. Zhao, M.J. Gong, et al., Antiviral activity of porcine interferon omega 7 against foot-and-mouth disease virus in vitro, J. Med. Virol. (2018) 1-7.

[13] S.T. de Los, S.F. Diaz-San, L.L. Rodriguez, The need for improved vaccines against foot-and-mouth disease, Curr. Opin. Virol. 29 (2018) 16-25.

[14] S.M. Kim, J.H. Park, K.N. Lee, et al., Enhanced inhibition of foot-and-mouth disease virus by combinations of porcine interferon-alpha and antiviral agents, Antivir. Res. 96 (2012) 213-220.

[15] S. Rafiei, S.E. Rezatofighi, M.R. Ardakani, O. Madadgar, In vitro anti-foot-andmouth disease virus activity of magnesium oxide nanoparticles, IET Nanobiotechnol. 9 (2015) 247-251.

[16] M.I. Gismondi, X.P. Ortiz, A.P. Curra, et al., Artificial microRNAs as antiviral strategy to FMDV: structural implications of target selection, J. Virol. Methods 199 (2014) 1-10.

[17] K. Gibbert, J.F. Schlaak, D. Yang D, U. Dittmer, IFN-alpha subtypes: distinct biological activities in anti-viral therapy, Br. J. Pharmacol. 168 (2013) 1048-1058.

[18] K.Y. Fung, N.E. Mangan, H. Cumming, et al., Interferon-epsilon protects the female reproductive tract from viral and bacterial infection, Science 339 (2013) 1088-1092.

[19] A. Demers, G. Kang, F. Ma, et al., The mucosal expression pattern of interferonepsilon in rhesus macaques, J. Leukoc. Biol. 96 (2014) 1101-1107.

[20] P. Hermant, C. Francius, F. Clotman, T. Michiels, IFN-epsilon is constitutively expressed by cells of the reproductive tract and is inefficiently secreted by fibroblasts and cell lines, PLoS One 8 (2013) e71320.

[21] X. He, T. Korytar, J. Schatz, et al., Anti-lyssaviral activity of interferons kappa and omega from the serotine bat, Eptesicus serotinus, J. Virol. 88 (2014) 5444-5454.

[22] L. Ramírez-Carvajal, F. Diaz-San Segundo, E. Ramirez-Medina, et al., Constitutively active IRF7/IRF3 fusion protein completely protects swine against foot-and-mouth disease, J. Virol. 90 (2016) 8809-8821.

[23] W.M. Schneider, M.D. Chevillotte, C.M. Rice, Interferon-stimulated genes: a complex web of host defenses, Annu. Rev. Immunol. 32 (2014) 513-545. 